\section{Changes in hindgut $\mathrm{pH}$ of ponies following feeding with fructan carbohydrate in the form of inulin}

\author{
Carol Crawford', Andrew Dobson', Simon R. Bailey', \\ Patricia A. Harris ${ }^{2}$ and Jonathan Elliott'
}

Department of Veterinary Basic Sciences, Royal Veterinary College, London' and Equine Studies Group, WALTHAM Centre for Pet Nutrition², UK

\section{Introduction}

Fructans, the main storage form of carbohydrates found in many grasses, have been implicated in causing changes in the equine hindgut leading to the development of acute equine laminitis (Longland et al. 1999). The production of lactic acid, increasing the permeability of the large intestinal mucosa to toxins and larger molecules (Weiss et al. 2000), is thought to be important in this process. Understanding the quantities of fructan carbohydrate necessary to cause significant changes in hindgut $\mathrm{pH}$ will provide information which will be helpful in assessing the likely effects of grazing different forages on hindgut bacterial fermentation. The objective of this study was firstly to determine the concentrationdependent effect of inulin, a form of fructan, on caecal $\mathrm{pH}$ using an in vitro model. Secondly, an in vivo study was conducted where controlled amounts of inulin were fed to normal ponies and ponies predisposed to laminitis, to determine whether any differences would be seen in the hindgut $\mathrm{pH}$ changes.

\section{Materials and Methods}

Firstly, equine caecal contents, obtained from ponies euthanased for purposes unrelated to the study, were incubated in an anaerobic environment in vitro at $37^{\circ} \mathrm{C}$ ( Mk 3 anaerobic work station, Don Whitley Scientific Ltd., Basingstoke, UK) in several $100 \mathrm{ml}$ aliquots. No supplemental buffer was included. Inulin was added to the aliquots in quantities ranging from from 0-10 g/litre, and the $\mathrm{pH}$ was measured at 6 hour intervals for 24 hours.

For the in vivo studies, 11 non-obese adult native breed ponies were used, 5 normals and 6 ponies predisposed to laminitis, but not affected by the condition at the time of the study. Following an initial period of 2 weeks on a basal hay diet, inulin was then fed at $1 \mathrm{~g}$ or $3 \mathrm{~g} / \mathrm{kg}$ bodyweight (BW), fed either once daily $(1 \mathrm{~g} / \mathrm{kg})$ or split into two equal feeds $(3 \mathrm{~g} / \mathrm{kg})$. Hay was provided ad lib, and a high protein dried grass (15\% protein) was fed as one third of the forage ration, to provide an amino acid source which would mimic that present in lush grass. Faecal $\mathrm{pH}$ was measured twice daily throughout the study period.

\section{Results}

Inulin produced a dose-dependent decrease in the $\mathrm{pH}$ of caecal contents in vitro, from a baseline of $7.0 \pm 0.2$ to a minimum of $4.9 \pm 0.3$, when inulin was added at $10 \mathrm{~g} /$ litre (Figure 1). In the in vivo study, none of the animals showed signs of laminitis or any other clinical problem. When inulin was fed at $1 \mathrm{~g} / \mathrm{kg} \mathrm{BW}$, faecal $\mathrm{pH}$ decreased from 7.0 0.1 to $6.4 \pm 0.1$ after 3 days (Figure 2), and at $3 \mathrm{~g} / \mathrm{kg} \mathrm{BW}$, the $\mathrm{pH}$ decreased from $6.8 \pm 0.1$ to a minimum of $6.3 \pm 0.1$ (Figure 3). There were no significant differences between the normal ponies and those predisposed to laminitis.

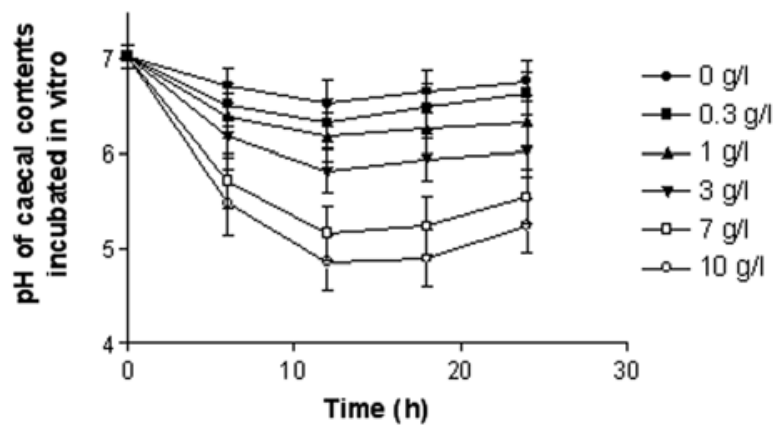

Fig 1 Effect of addition of inulin on $\mathrm{pH}$ change in equine caecal contents.

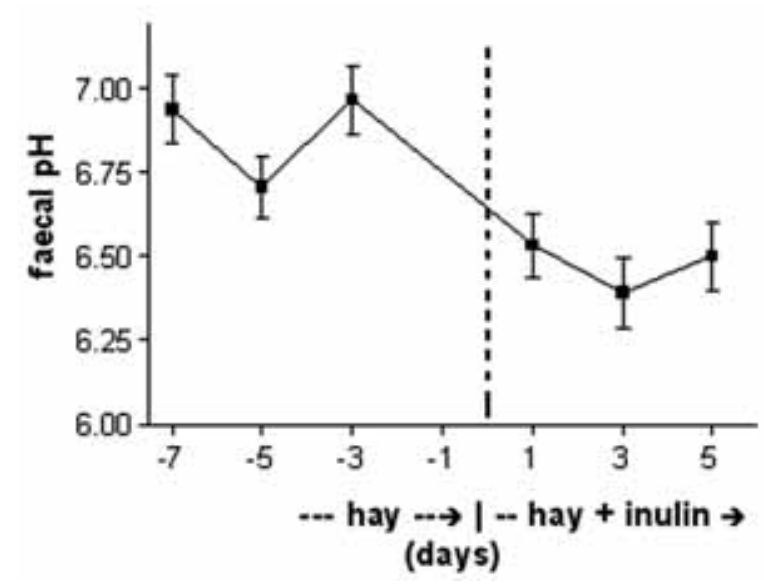

Fig 2 Effect of feeding inulin to ponies, at $1 \mathrm{~g} / \mathrm{kg}$ bodyweight, on faecal $\mathrm{pH}$.

\section{Discussion}

These data demonstrate the changes in hindgut $\mathrm{pH}$ in response to the addition of varying amounts of fructan carbohydrates in vitro and in vivo. Feeding inulin at $3 \mathrm{~g} / \mathrm{kg}$ produced a slightly lower minimum faecal $\mathrm{pH}$ value, compared with feeding $1 \mathrm{~g} / \mathrm{kg}$, although this was not significantly different. This amount of inulin is well below the amount reported to cause laminitis by bolus administration (greater than $7.5 \mathrm{~g} / \mathrm{kg}$; French and Pollitt 2004). However, this model may mimic some of the changes in carbohydrate fermentation by hindgut bacteria following grazing of ponies on lush grass. 


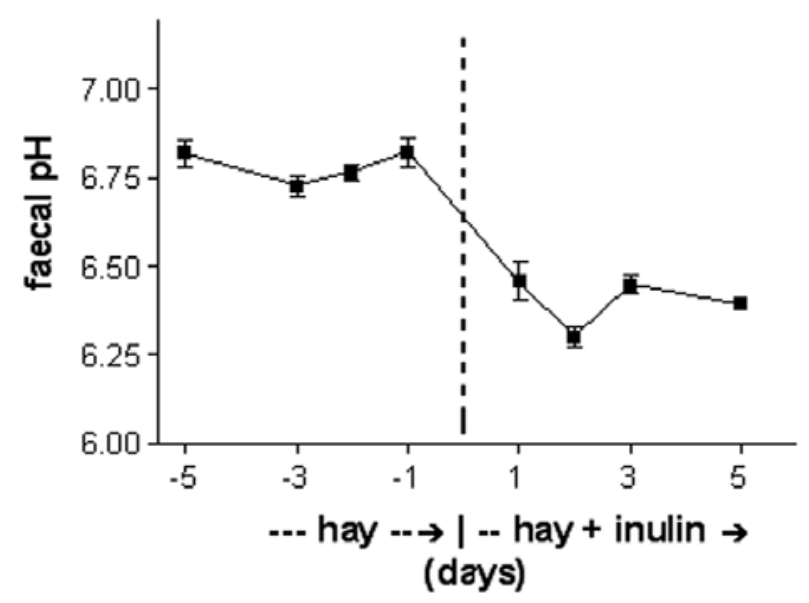

Fig 3 Effect of feeding inulin to ponies, at $3 \mathrm{~g} / \mathrm{kg}$ bodyweight, on faecal $\mathrm{pH}$.

\section{Conclusions}

There was no evidence of differences in faecal $\mathrm{pH}$ in ponies predisposed to developing laminitis, compared to normal ponies. Therefore, production of lactic acid in the hindgut per se, may not be the only factor which renders particular animals prone to laminitis. Other factors may be involved, for example the production, absorption, and activity of other bacterial toxins, such as amine compounds (Bailey et al. 2002).

\section{References}

Bailey S. R., Rycroft A. and Elliott J. (2002): Production of amines in equine cecal contents in an in vitro model of carbohydrate overload. Journal of Animal Science 80, 2656-62

French K. R. and Pollitt C. C. (2004): Equine laminitis: loss of hemidesmosomes in hoof secondary epidermal lamellae correlates to dose in an oligofructose induction model: an ultrastructural study. Equine Veterinay Journal 36, 230-5

Longland A. C., Cairns, A. J. and Humphreys M. O. (1999): Seasonal and diurnal changes in fructan concentration in Lolium perenne: implications for the grazing management of equines predisposed to laminitis. In: Proceedings of the 16th Equine Nutritional Physiology Society Meeting, Raleigh, NC, 258-259

Weiss D. J., Evanson O. A., Green B. T. and Brown D. R. (2000): In vitro evaluation of intraluminal factors that may alter intestinal permeability in ponies with carbohydrate-induced laminitis. American Journal of Veterinary Research 61, 858-61

\author{
S. R. Bailey \\ Department of Veterinary Basic Sciences \\ Royal Veterinary College, London \\ srbailey@rvc.ac.uk
}

